\title{
CCL5 rs2107538 Polymorphism Increased the Risk of Tuberculosis in a Sample of Iranian Population
}

\author{
Hamid Reza Kouhpayeh', Mohsen Taheri ${ }^{2,3}$, Mana Baziboroon', \\ Mohammad Naderi', Gholamreza Bahari ${ }^{4}$, Mohammad Hashemi ${ }^{4}$ \\ ${ }^{1}$ Infectious Diseases and Tropical Medicine Research Center, Zahedan University \\ of Medical Sciences, Zahedan, Iran; \\ ${ }^{2}$ Genetics of Non-Communicable Disease Research Center, Zahedan University \\ of Medical Sciences, Zahedan, Iran; \\ ${ }^{3}$ Department of Genetic, School of Medicine, Zahedan University of Medical \\ Sciences, Zahedan, Iran; \\ ${ }^{4}$ Department of Clinical Biochemistry, School of Medicine, Zahedan University \\ of Medical Sciences, Zahedan, Iran
}

Received April 21, 2016; Accepted September 2, 2016.

Key words: Tuberculosis - CCL5 - CCR5 - Polymorphism

\begin{abstract}
Cysteine-cysteine chemokine ligand 5 (CCL5) with immunoregulatory and inflammatory activities has an important role in granuloma formations that activates and stimulates T-cells and macrophages. Cysteine-cysteine chemokine receptor 5 (CCR5) is a chemokine receptor, which is important for migration of immune cells to site of infection. In the present study we investigated the possible association between CCL5 -403G/A (rs2107538), CCL5 -28C/G (rs2280788) and CCR5 $\Delta 32$ polymorphisms and pulmonary tuberculosis (PTB) in an Iranian population. This case-control study was performed on 160 patients with pulmonary tuberculosis and 160 unrelated healthy subjects. The CCL5 $-403 \mathrm{G} / \mathrm{A}, \mathrm{CCL} 5-28 \mathrm{C} / \mathrm{G}$ and CCR5 $\Delta 32$ polymorphisms were genotyped by allele-specific polymerase chain reaction (AS-PCR), tetra amplification refractory mutation system polymerase chain reaction (T-ARMS PCR) and PCR, respectively. Our results showed that GA as well as GA+AA genotypes of CCL5 $-403 \mathrm{G} / \mathrm{A}$ ( $r$ 2107538) increased the risk of PTB in comparison with GG genotype $(\mathrm{OR}=1.70,95 \% \mathrm{Cl}=1.03-2.81, \mathrm{P}=0.038$ and $\mathrm{OR}=1.64,95 \% \mathrm{Cl}=1.00-2.68, \mathrm{P}=0.049$,
\end{abstract}

This study was supported by dissertation grant (MD. thesis of MB) from Zahedan University of Medical Sciences, Zahedan, Iran.

Mailing Address: Assoc. Prof. Mohsen Taheri, PhD., Department of Genetic, School of Medicine, Zahedan University of Medical Sciences, Zahedan 98167-43463, Iran; e-mail: mohsen.taheri.gene@gmail.com 
respectively). No significant association was found between CCL5 $-28 \mathrm{C} / \mathrm{G}$ as well as CCR5 $\triangle 32$ polymorphism and PTB risk. In conclusion, our findings proposed that CCL5 -403G>A polymorphism may be a risk factor for susceptibility to PTB in our population. Larger sample sizes with different ethnicities are required to validate our findings.

\section{Introduction}

Tuberculosis (TB) is one of the most communicable diseases in humans caused by various strains of mycobacteria frequently Mycobacterium tuberculosis. According to the World Health Organization (WHO) report, most of the estimated number of TB cases occurred in Asia (55\%) and Africa (30\%). TB with 8 million new cases and 1.5 million deaths worldwide annually remains as a major global health problem (Millet et al., 2013). Though one third of human infected with Mycobacterium tuberculosis, only $10 \%$ of the infected persons develop the clinical disease (Cobat et al., 2013). Cumulative evidence designates that in addition to the environment, host genetic factors play an important role in susceptibility to TB (Bahari et al., 2012; Hashemi et al., 2013a, 2015; Naderi et al., 2014a, b).

It is well known that chemokines are essential regulators of immune system in response to Mycobacterium tuberculosis infectious. CCL5 is an $8 \mathrm{kDa}$ protein belongs to the CC chemokines family and known as RANTES (Regulated on Activation, Normal T-cell Expressed and Secreted). CCL5 is chemotactic for T-cells as well as macrophages and mediate the migration and activation of these cells into inflammatory sites (Alqumber et al., 2013). It is a main chemokine involved in both the acute and chronic phase of inflammation and possibly participate in pathogenesis and formation of granuloma during infection with Mycobacterium tuberculosis (Méndez-Samperio, 2008). Indeed, this chemokine may have a role in the inhibition of intracellular growth of Mycobacterium tuberculosis (Chu et al., 2007). The human CCL5 mapped to chromosome 17 (17q11.2-q12) and consist of three exons and two introns. This gene is polymorphic and have been suggested that two polymorphisms in promoter region $(-403 \mathrm{G} / \mathrm{A}$ and $-28 \mathrm{C} / \mathrm{G})$ effect the expression of CCL5 (Chu et al., 2007).

CCR5 or CD195 is a member of the beta chemokine receptor family. This protein is expressed by T-cells, macrophages, immature dendritic cells and granulocytes and has an important role in inflammatory response to infection (Carpenter et al., 2014). It has been reported that CCR5 is overexpressed in PTB (pulmonary tuberculosis) patients in comparison with normal subjects (Mamtani et al., 2011). The ligands of this receptor are CCL5 (RANTES), macrophage inflammatory protein (MIP-1 $\alpha$ and MIP-1 $\beta$ or CCL3 and CCL4) and CCL3L1 (Han et al., 2012). The CCR5 gene is located on short arm of chromosome 3 at the chemokine receptor gene cluster region (Mishra et al., 2012). Several polymorphisms have been recognized in CCR5 which one of them is CCR5-delta32 
(CCR5 $\Delta 32$ ). CCR5 $\Delta 32$ is a deletion of gene results in a non-functional receptor form of the chemokine receptor that is unable to bind CC chemokine ligands such as CCL5. Numerous studies have shown the association of CCL5 and CCR5 gene polymorphism and the risk of TB in various ethnic populations, but the results were controversial (Ben-Selma et al., 2011; Selvaraj et al., 2011; Carpenter et al., 2014). Therefore, the present case-control study was designed to investigate the possible association between CCL5 -403G/A (rs2107538), CCL5 -28C/G (rs2280788) and CCR5 $\Delta 32$ polymorphisms and pulmonary tuberculosis in a sample of southeast Iranian population.

\section{Material and Methods}

Patients

This case-control study was done from June 2012 to September 2013 on patients who referred to Bou-Ali Hospital (referral center for TB, Zahedan, Iran). A total of 320 subjects including 160 confirmed PTB and 160 unrelated healthy subjects with no clinical symptoms or history of TB and living in the same area as the patients with PTB (Southeast Iran) were enrolled in the study. Informed consent was taken from all subjects and the project was approved by Ethics Committee of Zahedan University of Medical Sciences. TB was diagnosed by clinical symptoms, posterioranterior chest radiography, presence of acid-fast-bacilli (AFB) on a sputum smear, culturing Mycobacterium tuberculosis organisms from a specimen taken from the patient and response to antituberculosis chemotherapy as described in our previous study (Kouhpayeh et al., 2012). DNA was extracted from whole blood samples using salting out method as described previously (Hashemi et al., 2013b).

\section{Genotyping}

CCL5 -403G/A (rs2107538) as well as CCR5 $\Delta 32$ polymorphisms were genotyped using allele specific PCR (AS-PCR) and PCR method as described previously (Eskandari-Nasab et al., 2014). Briefly, primers for the CCL5 -403G/A (rs2107538) polymorphism were as follows: reverse (command):TTCTTGGGGACAACAAGGAG, forward (A allele): GGATGAGGGAAAGGCGA and forward (G allele): GGATGAGGGAAAGGCGG. The forward and reverse primers for detection of $32 \mathrm{bp}$ ins/del polymorphism were 5'-TCAAAAAGAAGGTCTTCATTACACC-3' and 5'-AGCCCAGAAGAGAAAATAAACAATC-3', respectively.

For detection of CCL5 -28C/G (rs2280788) variant we designed a tetra amplification refractory mutation system polymerase chain reaction (T-ARMS PCR). We used two external primers (forward outer: 5'-AGGAGCGCAGAGGGCAGTAGCAATGA-3', reverse outer: 5'-TGAGGAGGACCCCTTCCCTGGAAGGT-3') and two internal primers (forward inner [C allele]: 5'-GGAATGAAAAATTAGAACAACAGAACCA-3' reverse inner [G allele]: 5'-TTTGCTAAAGAAATAGAAGTGGCTTACAAC-3'). 
PCR was performed in $25 \mu \mathrm{l}$ reaction volumes containing $0.4 \mu \mathrm{M}$ of each primer, $250 \mu \mathrm{M}$ of each dNTP, $1 \cup \mathrm{Taq}$ DNA polymerase with $2 \mathrm{mM} \mathrm{MgCl}$, and $50 \mathrm{ng}$ genomic DNA. The PCR cycling conditions was as follows: an initial denaturation step of $5 \mathrm{~min}$ at $95^{\circ} \mathrm{C}$ followed by 30 cycles of $30 \mathrm{~s}$ at $95{ }^{\circ} \mathrm{C}$, annealing at $54^{\circ} \mathrm{C}$ for $30 \mathrm{~s}$ and extension at $72{ }^{\circ} \mathrm{C}$ for $30 \mathrm{~s}$. Final extension was performed at $72{ }^{\circ} \mathrm{C}$ for $5 \mathrm{~min}$. The PCR products were separated by electrophoresis in $2 \%$ agarose gels, and observed under ultraviolet light. Product sizes were 272 bp for $C$ allele and $181 \mathrm{bp}$ for $\mathrm{G}$ allele, whereas the product size of the two outer primers was $400 \mathrm{bp}$.

\section{Statistical analysis}

Statistical analysis was performed by SPSS software V18.0. In order to investigate potential association of the selected polymorphism with tuberculosis, the allele and genotype frequencies in patients and healthy controls were compared using Pearson's chi-squared test. Logistic regression analysis was applied to estimate odds ratio $(\mathrm{OR})$ and $95 \%$ confidence intervals $(\mathrm{Cl})$ of genetic risk in PTB. P-values less than 0.05 were considered statistically significant.

\section{Results}

The study groups consist of 160 PTB patients (77 males and 83 females) and 160 control subjects (59 males and 101 females). Mean age of PTB patients and control groups were $48.78 \pm 20.374$ and $47.68 \pm 15.86$, respectively. No significant difference was seen between two groups regarding age and sex $(P=0.592$ and 0.054 , respectively).

The genotype and allele frequency of CCL5 -403G/A polymorphism is shown in Table 1.The results indicated that GA as well as GA+AA genotype increased the risk of PTB in comparison with $\mathrm{GG}$ genotype $(\mathrm{OR}=1.70,95 \% \mathrm{Cl}=1.03-2.81$, $\mathrm{P}=0.038$ and $\mathrm{OR}=1.64,95 \% \mathrm{Cl}=1.00-2.68, \mathrm{P}=0.049$, respectively). The allele frequency of CCL5 $-403 \mathrm{G} / \mathrm{A}$ polymorphism was not significantly different between the groups $(\mathrm{P}=0.08)$.

The genotype frequency of CCL5 $-28 C / G$ polymorphism showed that all PTB patients and healthy controls had GG genotype which indicates that this variant is not polymorphic in our population.

The analysis of the PTB patients and healthy controls revealed no statistically significant difference between the groups regarding 32 bp insertion/deletion polymorphism of the CCR5 gene. In each groups 154 persons has Ins/Ins genotypes and 6 has Ins/Del (Table 2). Our finding demonstrated that the 32 bp deletion polymorphism of CCR5 is not a risk factor for PTB.

\section{Discussion}

Tuberculosis after HIV is the second leading cause of death worldwide and killing about 2 million people annually (Millet et al., 2013). Besides of environment factor 
Table 1 - The genotypes and allele distribution of CCL5 -403G>A polymorphisms in pulmonary tuberculosis (PTB) patients and control groups

\begin{tabular}{|c|c|c|c|c|}
\hline $\begin{array}{l}\text { Polymorphism } \\
\text { CCL5 -403G>A }\end{array}$ & $\begin{array}{l}\text { Patients } \\
\text { n (\%) }\end{array}$ & $\begin{array}{c}\text { Normal } \\
\text { n (\%) }\end{array}$ & OR $(95 \% \mathrm{Cl})$ & $\mathrm{P}$ \\
\hline \multicolumn{5}{|c|}{ Codominant } \\
\hline GG & $104(65)$ & $121(75.6)$ & 1.00 & \\
\hline GA & $54(33.8)$ & $36(22.5)$ & $1.70(1.03-2.81)$ & 0.038 \\
\hline AA & $2(1.2)$ & $3(1.9)$ & $0.82(0.13-5.05)$ & 0.827 \\
\hline \multicolumn{5}{|c|}{ Dominant } \\
\hline GG & $104(65)$ & $121(75.6)$ & 1.00 & \\
\hline $\mathrm{GA}+\mathrm{AA}$ & $56(35)$ & $39(24.4)$ & $1.64(1.00-2.68)$ & 0.049 \\
\hline \multicolumn{5}{|c|}{ Recessive } \\
\hline $\mathrm{GG}+\mathrm{GA}$ & $158(98.8)$ & 157 (98.1) & 1.00 & \\
\hline AA & $2(1.2)$ & $3(1.9)$ & $1.43(1.04-2.58)$ & 0.369 \\
\hline \multicolumn{5}{|c|}{ Alleles } \\
\hline G & 262 (81.9) & 278 (86.9) & & \\
\hline A & $58(18.1)$ & 42 (13.1) & & \\
\hline
\end{tabular}

Table 2 - The genotypes and allele distribution of CCR5 $\Delta 32$ polymorphisms in pulmonary tuberculosis (PTB) patients and control groups

\begin{tabular}{lcccc}
\hline $\begin{array}{l}\text { Polymorphism } \\
\text { CCR5 } \Delta 32\end{array}$ & $\begin{array}{c}\text { Patients } \\
\mathrm{n}(\%)\end{array}$ & $\begin{array}{c}\text { Normal } \\
\mathrm{n}(\%)\end{array}$ & OR $(95 \% \mathrm{Cl})$ & $\mathrm{P}$ \\
\hline WW & \multicolumn{5}{c}{ Codominant } & \\
WD & $154(96.25)$ & $154(96.25)$ & 1.00 & 0.92 \\
DD & $6(3.7)$ & $6(3.7)$ & $1.05(0.33-3.40)$ & - \\
\hline W & $0(0)$ & $0(0)$ & & \\
D & $308(96.25)$ & $308(96.25)$ & \\
\hline
\end{tabular}

OR - odds ratio (adjusted for sex and age); $\mathrm{Cl}$ - confidence interval

and virulence of pathogen, the differences in host immune genes polymorphisms has been proposed to play a key role in determining TB susceptibility (Möller and Hoal, 2010). In the present study, we investigated the possible association between CCL5 -403G/A (rs2107538), CCL5 -28C/G (rs2280788) and CCR5 $\Delta 32$ gene polymorphisms and susceptibility to PTB in a sample of Iranian population. 
To the best of our knowledge this is the first genetic association study regarding the relationship between polymorphism in CCL5 and CCR5 genes and PTB in a sample of Iranian population. Our results showed that GA (in the codominant model) as well as GA+AA (in the dominant model) genotypes of CCL5 rs2107538 were associated with increased risk of PTB. The findings of this study indicated no significant association between CCL5 rs2280788 variant as well as CCR5 $\Delta 32$ polymorphism and PTB risk. In contrast to our finding Mhmoud et al. (2013) showed significant differences in allele distribution of CCL5 -28C/G ( $r s 2280788$ ) in TB patients compared with healthy controls. They found that $G$ allele was more frequently in the patient population. However, they didn't detect any association between CCL5 rs2107538-403G/A polymorphism and TB. The CCL5 -28G probably increased promoter activity and CCL5 expression. In agreements to our study, Mishra et al. (2012) showed that the frequency of AA genotype and A allele in CCL5 -403G/A polymorphism were significantly higher in cases than controls, thus they supposed that this polymorphism may be associated with susceptibility to TB. Also they found that CCL5 -28G/A was not associated with resistance or susceptibility to TB. Chu et al. (2007) showed that the distribution of CCL5 $-28 \mathrm{C} / \mathrm{G}$ and $-403 \mathrm{G} / \mathrm{A}$ polymorphisms was not associated with TB susceptibility in Hong Kong Chinese population. Selvaraj et al. (2011) revealed that allele and genotype frequencies of CCL5 $-403 \mathrm{G} / \mathrm{A}$ and $-28 \mathrm{C} / \mathrm{G}$ polymorphisms were not different between PTB patients and healthy individuals. Whereas, Ben-Selma et al. (2011) findings indicated an association of the CCL5 $-28 \mathrm{C} / \mathrm{G}$ and $-403 \mathrm{G} / \mathrm{A}$ polymorphisms with susceptibility to TB infection in Tunisian populations. They found that $-28 \mathrm{G} / \mathrm{C}$ polymorphism was significantly associated with PTB susceptibility. They reported that $-28 \mathrm{CC}$ genotype decreased PTB risk while $-403 \mathrm{~A}$ allele increased the risk of PTB development. Sánchez-Castañón et al. (2009) identified that the frequency of the CCL5 -403G/A and $-28 C / G$ promoter polymorphisms were significantly different between PTB patients and control subjects. They observed that $-403 \mathrm{G} / \mathrm{G}$ and $-28 \mathrm{C} / \mathrm{C}$ genotypes as well as $-403 \mathrm{G}$ allele and $-28 \mathrm{C}$ allele were significantly more frequent in control subjects. Carpenter et al. (2014) didn't find any association between CCR5 polymorphism and susceptibility to clinically active TB. Mishra et al. (2012) have found no significant association between CCR5 polymorphism with either resistance or susceptibility to TB in Sahariya tribe of north central India population. Mamtani et al. (2011) have found an association between CCR5 gene polymorphisms and risk of TB.

During infection by Mycobacterium tuberculosis some chemokines including MCP-1 and CCL5 recruiting T-cells and macrophages to sites of TB infection and have important role in the formation of granuloma which enclose and control distribution of TB (Selvaraj et al., 2011). CCL5 concentration increase in PTB patients and decreased during period of recovery which indicate that play a key role in the immune response against TB infection. CCL5 function at a 
precise concentration and production of CCL5 over or under this concentration accompanied with dysfunction of this chemokine (Chu et al., 2007). It is plausible that $-403 \mathrm{G} / \mathrm{A}$ and $-28 \mathrm{C} / \mathrm{G}$ polymorphisms affect the expression of CCL5 and might be associated with development of TB. Also polymorphisms in CCR5 cause alteration in binding of this receptor to its ligands such as CCL5 (Mamtani et al., 2011).

In summary, our study showed that CCL5 -403G/A (rs2107538) polymorphism might be a candidate gene, which determines the susceptibility to PTB in our population. Whereas CCL5 -28C/G (rs2280788) and CCR5 $\Delta 32$ polymorphisms may not be major genetic factors for susceptibility to PTB. Further investigations with different ethnicities and larger sample sizes are needed to validate our findings.

Acknowledgements:The authors thank to the patients and healthy subjects who willingly participated in the study.

\section{References}

Alqumber, M. A., Mandal, R. K., Haque, S., Panda, A. K., Akhter, N., Ali, A. (2013) A genetic association study of CCL5 -28 C>G (rs2280788) polymorphism with risk of tuberculosis: a meta-analysis. PLoS One 8(12), e83422.

Bahari, G., Hashemi, M., Taheri, M., Naderi, M., Eskandari-Nasab, E., Atabaki, M. (2012) Association of IRGM polymorphisms and susceptibility to pulmonary tuberculosis in Zahedan, Southeast Iran. ScientificWorldJournal 2012, 950801.

Ben-Selma, W., Harizi, H., Bougmiza, I., Ben Kahla, I., Letaief, M., Boukadida, J. (2011) Polymorphisms in the RANTES gene increase susceptibility to active tuberculosis in Tunisia. DNA Cell Biol. 30(10), 789-800.

Carpenter, D., Taype, C., Goulding, J., Levin, M., Eley, B., Anderson, S., Shaw, M. A., Armour, J. A. (2014) CCL3L1 copy number, CCR5 genotype and susceptibility to tuberculosis. BMC Med. Genet. 15, 5.

Chu, S. F., Tam, C. M., Wong, H. S., Kam, K. M., Lau, Y. L., Chiang, A. K. (2007) Association between RANTES functional polymorphisms and tuberculosis in Hong Kong Chinese. Genes Immun. 8(6), 475-479.

Cobat, A., Orlova, M., Barrera, L. F., Schurr, E. (2013) Host genomics and control of tuberculosis infection. Public Health Genomics 16(1-2), 44-49.

Eskandari-Nasab, E., Hashemi, M., Ebrahimi, M., Amininia, S., Bahari, G., Mashhadi, M. A., Taheri, M. (2014) Evaluation of CCL5 $-403 \mathrm{G}>\mathrm{A}$ and CCR5 $\Delta 32$ gene polymorphisms in patients with breast cancer. Cancer Biomark. 14(5), 343-351.

Han, S.W., Sa, K. H., Kim, S. I., Lee, S. I., Park, Y.W., Lee, S. S., Yoo, W. H., Soe, J. S., Nam, E. J., Lee, J., Park, J.Y., Kang, Y. M. (2012) CCR5 gene polymorphism is a genetic risk factor for radiographic severity of rheumatoid arthritis. Tissue Antigens 80(5), 416-423.

Hashemi, M., Eskandari-Nasab, E., Moazeni-Roodi, A., Naderi, M., Sharifi-Mood, B., Taheri, M. (2013a) Association of CTSZ rs34069356 and MC3R rs6127698 gene polymorphisms with pulmonary tuberculosis. Int. J. Tuberc. Lung Dis. 17(9), 1224-1228.

Hashemi, M., Hanafi Bojd, H., Eskandari-Nasab, E., Bahari, A., Hashemzehi, N. A., Shafieipour, S., Narouie, B., Taheri, M., Ghavami, S. (2013b) Association of adiponectin rs1501299 and rs266729 gene polymorphisms with nonalcoholic fatty liver disease. Hepat. Mon. 13(5), e9527.

Hashemi, M., Sharifi-Mood, B., Rasouli, A., Amininia, S., Naderi, M., Taheri, M. (2015) Macrophage migration 
inhibitory factor $-173 \mathrm{G} / \mathrm{C}$ polymorphism is associated with an increased risk of pulmonary tuberculosis in Zahedan, Southeast Iran. EXCLI J. 14, 117-122.

Kouhpayeh, H. R., Hashemi, M., Hashemi, S. A., Moazeni-Roodi, A., Naderi, M., Sharifi-Mood, B., Taheri, M., Mohammadi, M., Ghavami, S. (2012) R620W functional polymorphism of protein tyrosine phosphatase non-receptor type 22 is not associated with pulmonary tuberculosis in Zahedan, southeast Iran. Genet. Mol. Res. 11(2), 1075-1081.

Mamtani, M., Mummidi, S., Ramsuran, V., Pham, M. H., Maldonado, R., Begum, K., Valera, M. S., Sanchez, R., Castiblanco, J., Kulkarni, H., Ndung'u, T., He, W., Anaya, J. M., Ahuja, S. K. (2011) Influence of variations in CCL3L1 and CCR5 on tuberculosis in a northwestern Colombian population. J. Infect. Dis. 203(11), 1590-1594.

Méndez-Samperio, P. (2008) Expression and regulation of chemokines in mycobacterial infection. J. Infect. 57(5), 374-384.

Mhmoud, N., Fahal, A., van de Sande, W. J. (2013) Association of IL-10 and CCL5 single nucleotide polymorphisms with tuberculosis in the Sudanese population. Trop. Med. Int. Health 18(9), 1119-1127.

Millet, J. P., Moreno, A., Fina, L., del Bano, L., Orcau, A., de Olalla, P. G., Cayla, J. A. (2013) Factors that influence current tuberculosis epidemiology. Eur. Spine J. 22, 539-548 (Suppl. 4).

Mishra, G., Poojary, S. S., Raj, P., Tiwari, P. K. (2012) Genetic polymorphisms of CCL2, CCL5, CCR2 and CCR5 genes in Sahariya tribe of North Central India: an association study with pulmonary tuberculosis. Infect. Genet. Evol. 12(5), 1120-1127.

Möller, M., Hoal, E. G. (2010) Current findings, challenges and novel approaches in human genetic susceptibility to tuberculosis. Tuberculosis (Edinb.) 90(2), 71-83.

Naderi, M., Hashemi, M., Pourmontaseri, Z., Eskandari-Nasab, E., Bahari, G., Taheri, M. (2014a) TIRAP rs8177374 gene polymorphism increased the risk of pulmonary tuberculosis in Zahedan, southeast Iran. Asian Pac. J.Trop. Med. 7(6), 451-455.

Naderi, M., Hashemi, M., Taheri, M., Pesarakli, H., Eskandari-Nasab, E., Bahari, G. (2014b) CD209 promoter $-336 \mathrm{~A} / \mathrm{G}$ ( $\mathrm{rs} 4804803)$ polymorphism is associated with susceptibility to pulmonary tuberculosis in Zahedan, southeast Iran. J. Microbiol. Immunol. Infect. 47(3), 171-175.

Sánchez-Castañón, M., Baquero, I. C., Sánchez-Velasco, P., Fariñas, M. C., Ausín, F., Leyva-Cobián, F., Ocejo-Vinyals, J. G. (2009) Polymorphisms in CCL5 promoter are associated with pulmonary tuberculosis in northern Spain. Int. J. Tuberc. Lung Dis. 13(4), 480-485.

Selvaraj, P., Alagarasu, K., Singh, B., Afsal, K. (2011) CCL5 (RANTES) gene polymorphisms in pulmonary tuberculosis patients of south India. Int. J. Immunogenet. 38(5), 397-402. 